\title{
Redação Científica de Artigos: Problemas Comuns
}

\author{
Scientific Writing Articles: Common Problems
}

\author{
Redacción de artículos científicos: problemas comunes
}

A publicação de um artigo científico é o produto final de um trabalho intelectual, assim como a redação científica de um artigo reflete a qualidade deste produto e da pesquisa que o sustenta (Diez-Ewald, 2011). De fato, a redação científica não é uma atividade fácil, mesmo para os mais experientes. Requer esforço, revisões frequentes, tempo para amadurecer os achados e sensibilidade para lidar com as críticas pertinentes.

A quantidade e citações de trabalhos científicos refletem o movimento típico de atualização de conhecimentos gerados nas pesquisas básicas e aplicadas (Ortinau, 2011). Pesquisadores valem-se do trabalho de seus antecessores e contemporâneos, visíveis para a comunidade, em geral, por meio dos artigos publicados, para continuarem o processo de construção e divulgação do conhecimento científico, úteis não somente aos cientistas, mas também a alunos e docentes, planejadores e gestores de políticas, ações e programas, profissionais que necessitam de dados e informações técnicas relevantes à intervenção especializada e, ainda, curiosos em geral.

Em programas de pós-graduação stricto sensu, no Brasil e no mundo, pesquisadores e estudantes enfrentam, cotidianamente, a necessidade de publicar artigos científicos em periódicos qualificados, inclusive em língua estrangeira (o inglês, preferencialmente). Dentre os principais requisitos para a manutenção e crescimento de programas de pós-graduação stricto sensu está a produtividade acadêmica, vista como manifestação privilegiada da produção do conhecimento científico (Cruz et al, 2019; Luz, 2005).

Os padrões da pesquisa acadêmica têm mudado rapidamente nas últimas décadas e os requisitos para pesquisar e publicar artigos são utilizados frequentemente para avaliar programas e carreira científicas de docentes/pesquisadores nas universidades, assim como para a obter financiamento para projetos de pesquisa e inovação. $\mathrm{O}$ crescimento dos programas de pós-graduação no Brasil e as pressões por produtividade acadêmica acentuam a necessidade de publicação, em termos quantitativos, confrontando-se com a velocidade de editoração dos periódicos científicos que, embora tenham melhorado em termos de quantidade e qualidade (índice Qualis/Capes, especialmente), ainda enfrentam dificuldades de diferentes tipos: de financiamento e manutenção das rotinas de produção do periódico (a rPOT é uma revista trimestral), o alto volume de entrada de artigos, a dificuldade em obter pareceres entre os pares (excesso de recusas ou não respostas, cada vez mais numerosos) e o controle do tempo entre submissão e publicação dos artigos.

Infelizmente, destacam-se, dentre essas dificuldades, aquelas que dizem respeito à qualidade dos manuscritos submetidos à rPOT. De forma genérica, verifica-se alguns aspectos salientes. Em termos estruturais, percebe-se, ainda, a dificuldade de organizar o manuscrito segundo as regras estipuladas pela revista. Isso envolve não somente a indexação de documentos solicitados e o cuidado minucioso com a formatação do manuscrito, mas, especialmente a necessidade de zelo na organização da es- trutura do texto e das referências ao longo e ao final do artigo.

A escrita do resumo, por exemplo, é problema recorrente. O resumo tem por objetivo principal fornecer uma visão geral da investigação e é, frequentemente, o único elemento recuperado e/ou revisado nas bases de dados científicas. A leitura de um resumo de um artigo permite identificar o valor potencial ou a relevância da pesquisa e dos seus resultados (Pereira, 2013; Sousa, 2006). Os resumos de manuscritos enviados à rPOT carecem, em geral, de uma estrutura básica: contexto, objetivo, método, principais resultados e conclusões. De fato, há resumos organizados apenas com recortes do manuscrito, muitas vezes sem observar que as frases utilizadas podem não guardar ligação entre si, comprometendo, inclusive, o seu uso adequado no processo de recuperação em revisões de literatura.

Associa-se a esse problema a definição do título e das palavras-chave. No primeiro caso, pelo fato do título "descolar-se" do manuscrito, ou seja, não expressar o fenômeno e contexto da pesquisa realizada, especialmente quando se refere a construtos ou assuntos não tratados na pesquisa ou periféricos. As palavras-chaves, por sua vez, são descritores que ajudam na indexação do artigo em bases de dados científicas e estão disponíveis nos sistemas de thesaurus da DeCS (Descritores em Ciências da Saúde), MeSH (Medical Subject Headings) ou o Thesaurus of Psychological Index Terms (American Psychological Association [APA]), dentre os sistemas que mais utilizamos em Psicologia. Em função disso, ao defini-las, recomenda-se uma reflexão mais rigorosa das melhores opções de palavras-chaves, de forma a promover uma localização mais precisa do artigo nos sistemas de busca (Garcia, Gattaz, \& Gattaz, 2019).

Destaca-se, ainda, a necessidade de aperfeiçoar a compreensão da estrutura básica de um artigo: Introdução, Método, Resultados, Discussão e, se for o caso, Conclusão (ou considerações finais). Os artigos recebidos na rPOT são predominantes de delineamento empírico, o que significa dizer que essa estrutura básica deve ser atendida. Os problemas mais frequentes, nesse caso, podem ser resumidos da seguinte maneira:

a) A Introdução, que deveria refletir o estado da arte/pressupostos, perspectiva de discussão do artigo ou objetivo/propósito, nem sempre se mostra organizada nesse escopo. Com alguma frequência, o objetivo do artigo não reflete o título do artigo e os argumentos apresentados na Introdução que, por sua vez, mostra-se insuficiente para identificar o potencial e a relevância científica do artigo, o que refletirá, inclusive na perda de qualidade da Discussão;

b) $\mathrm{O}$ método, que tem por objetivo descrever o delineamento da pesquisa e seus componentes básicos (fontes primárias ou secundárias de dados, contexto, técnicas/instrumentos, procedimentos de coleta e análises de dados), são fontes permanente de críticas por parte dos pareceristas, especialmente por carecerem de detalhamento das estratégias/técnicas e instrumentos de coleta de dados utilizadas, do perfil dos participantes e do contexto de pesquisa, assim como dos procedimentos éti- 
cos seguidos. Muitas vezes, no método, não se verifica coerência entre os objetivos do estudo, o uso de determinadas técnicas ou instrumentos de coleta de dados e as análises propostas;

c) Os Resultados, que tem por objetivo caracterizar os dados coletados e os respectivos produtos das análises efetuadas, descritivamente e/ou por meio do uso de tabelas e figuras, frequentemente se apresentam "desconectados" dos objetivos ou hipóteses (muitas vezes implícitas) do artigo. Há a necessidade constante, no processo de avaliação e editoração do artigo, de solicitação de mudanças em tabelas e figuras: na adequação do título, no formato (normas da APA) e na organização do conteúdo (inadequação na comparação entre variáveis, ausência de informações estatísticas importantes, etc.);

d) A Discussão, uma das partes mais relevantes de um texto científico, tem por objetivo salientar as principais descobertas da pesquisa realizada frente aos objetivos perseguidos, confrontando-as com o estado da arte da produção científica especializada sobre o problema de pesquisa investigado. Nesse caso, observa-se que uma Discussão, quando não é bem realizada, revela a fragilidade principal do artigo, ou seja, quando os autores não desenvolvem argumentos claros e sustentados em comparações, contrastes e complementações com a literatura pertinente, frente aos resultados encontrados;

e) A Conclusão, em geral, é um breve texto, uma espécie de síntese das descobertas à luz do objetivo do artigo, identificando possíveis limitações e perspectivas de novos estudos. Contraditoriamente, verificam-se conclusões muitas vezes genéricas, sem relação com o propósito do estudo. Frequentemente, a Conclusão pode estar incluída na Discussão, desde que cumpra a sua finalidade precípua.

f) A normalização adequada das referências utilizadas, além dos aspectos formais de reconhecimento do mérito acadêmico e cumprimento das diretrizes e normas de formatação, adotadas pela Associação Americana de Psicologia (APA, 2012), é fundamental para o uso de indicadores corretos de hiperlink e DOI (Digital Object Identifier), essenciais para a diagramação do manuscrito e sua publicação. $O$ correto uso de referências é um importante critério para a citação de estudos em periódicos científicos, assim como para o uso da métricas internacionalmente adotadas (ex. fator de impacto, h-index, entre outros).

Do ponto de vista do conteúdo dos artigos, os problemas mais comuns podem ser identificados na fragilidade da escrita e qualidade na redação científica, com dificuldade em produzir argumentos suficientemente embasados em processos de análise e síntese dos achados. Dentre os problemas gramaticais, nota-se: o uso inadequado do gerúndio no início de frases ou parágrafos, sem conexão com argumentos anteriores; o excesso de parágrafos autorais (descrições seguidas de informações de uma mesma publicação em sequência, sem o devido confrontamento com as demais produções associadas); repetições de frases, frases desconexas, frases sem sujeito; uso excessivo de adjetivos (inúmeros, incontáveis, muitos) e advérbios de intensidade (bastante, grande); uso de conjunções adversativas no início de frases/parágrafos (apesar de, porém, mas, todavia, no entanto, contudo, etc.); o uso incorreto ou ausente de vírgulas (muitas vezes separando o sujeito do verbo principal) e ausência de crases; uso equivocado de termos: onde/aonde, esse/este, desse/deste, dentre outros.

Parágrafos bem construídos, assim como todo o texto, em geral, exigem coesão (coerência interna) e a coerência (relação entre os parágrafos) que permitem um fluxo de ideias/ argumentos. Portanto, parágrafos com uma única frase não permite desenvolver argumentos suficientes (frases isoladas), algo muito comum nos manuscritos enviados à publicação. Identificam-se, muitas vezes, que a urgência pelo envio de artigos à publicação contribui para a pouca maturidade dos argumentos produzidos, além dos costumeiros erros ortográficos.
Evidentemente que o conjunto desses problemas tornam o processo de avaliação e revisão acentuadamente graves, exigindo esforços dos editores e pareceristas para reduzir ao máximo os problemas referidos. De qualquer maneira, e independente das pressões por produtividade acadêmica, resta em todo esse processo a perspectiva pedagógica de auxiliar no aperfeiçoamento dos manuscritos enviados à rPOT.

Roberto Moraes Cruz

Editor-Chefe - Universidade Federal de Santa Catarina (UFSC), Brasil

Jairo Eduardo Borges-Andrade Editor Sênior - Universidade de Brasília (UnB), Brasil

Alexsandro Luiz De Andrade

Editor Associado - Universidade Federal do Espírito Santo (UFES), Brasil

Daniela Campos Bahia Moscon

Editora Associada - Universidade Federal da Bahia (UFBA), Brasil

Marcos Ricardo Datti Micheletto

Editor Associado - Universidade Estadual Paulista "Júlio de Mesquita Filho” (UNESP), Brasil

Nádia Kienen

Editora Associada - Universidade Estadual de Londrina (UEL),

Brasil

Germano Gabriel Lima Esteves

Editor Júnior - Universidade de Rio Verde (UniRV), Brasil

Paola Barros Delben

Editora Júnior - Universidade Federal de Santa Catarina (UFSC), Brasil

Maria Nivalda de Carvalho-Freitas

Presidente da Associação Brasileira de Psicologia Organizacional e do Trabalho (SBPOT), Brasil

\section{Referências}

American Psychological Association. (2012). Manual de Publicação da APA. Porto Alegre: Penso Editora.

Cruz, R. M., Borges-Andrade, J. E., Moscon, D. B., Micheletto, M. R. D., Sticca, M. G., Carlotto, M. S., ... \& Delben, P. B. (2019). Repercussões e desafios à produção da Revista Psicologia: Organizações e Trabalho. Revista Psicologia Organizações e Trabalho, 19(3), I-II. https://10.17652/rpot/2019.3.Editorial

Diez-Ewald, M. (2011). La redacción de un trabajo cientifico. Investigación Clínica, 52(3), 205-207.

Garcia, D. C. F., Gattaz, C. C., \& Gattaz, N. C. (2019). A Relevância do Título, do Resumo e de Palavras-chave para a Escrita de Artigos Científicos. Revista de Administração Contemporânea, 23(3), 1-9. https://doi.org/10.1590/ 1982-7849rac2019190178

Luz, M. T. (2005). Prometeu acorrentado: análise sociológica da categoria produtividade e as condições atuais da vida acadêmica. PHYSIS: Revista de Saúde Coletiva, 15, 39-57. Recuperado de https://www.scielosp.org/pdf/ physis/2005.v15n1/39-57/pt

Ortinau, D. J. (2011). Writing and publishing important scientific articles: A reviewer's perspective. Journal of Business Research, 64(2), 150-156. https://doi. org/10.1016/j.jbusres.2010.02.002

Pereira, M. G. (2013). O resumo de um artigo científico. Epidemiologia e Serviços de Saúde, 22(4), 707-708. https://doi.org/10.5123/S1679-49742013000400017

Sousa, V. D. (2006). Como escrever o resumo de um artigo para publicação. Acta Paulista de Enfermagem, 19(3), 5-8. https://doi.org/10.1590/S010321002006000300001 